\title{
High Levels of Cardiovascular Risk Factors among Pakistanis in Norway Compared to Pakistanis in Pakistan
}

\author{
Naeem Zahid, ${ }^{1,2}$ Haakon E. Meyer, ${ }^{2,3}$ Bernadette N. Kumar, ${ }^{2}$ \\ Bjørgulf Claussen, ${ }^{2}$ and Akhtar Hussain ${ }^{2}$ \\ ${ }^{1}$ Department of Gastrointestinal Surgery, Akershus University Hospital, Akershus, 1478 Lørenskog, Norway \\ ${ }^{2}$ Department of General Practice and Community Medicine, University of Oslo, 0316 Oslo, Norway \\ ${ }^{3}$ Norwegian Institute of Public Health, 0403 Oslo, Norway
}

Correspondence should be addressed to Naeem Zahid, naeemz78@hotmail.com

Received 22 November 2010; Accepted 3 May 2011

Academic Editor: Gianluca Iacobellis

Copyright (C) 2011 Naeem Zahid et al. This is an open access article distributed under the Creative Commons Attribution License, which permits unrestricted use, distribution, and reproduction in any medium, provided the original work is properly cited.

\begin{abstract}
Objectives. Previous studies have shown that the Norwegian-Pakistanis had considerably higher prevalence for diabetes and obesity compared to Norwegians. We studied the additional risk of obesity, dyslipidemia, and hypertension among Pakistanis in Norway compared to Pakistanis living in Pakistan. Method. 770 Norwegian-Pakistani adults (53.9\% men and 46.1\% women) born in Pakistan from two surveys conducted in Norway between 2000 and 2002 were compared with a sample of 1230 individuals (29.1\% men and $70.9 \%$ women) that participated in a survey in Pakistan in 2006. Results. Both populations had similar height, but Norwegian-Pakistanis had considerably higher mean weight. Of the Norwegian-Pakistanis, 56\% of the males and $40 \%$ of the females had a BMI above $25 \mathrm{~kg} / \mathrm{m}^{2}$, as opposed to $30 \%$ and $56 \%$ in Pakistan, for males and females, respectively. NorwegianPakistanis had higher total cholesterol. Conclusion. Obesity and an unfavourable lipid profile were widely prevalent in both populations; the highest level was recorded amongst those living in Norway. The increased risk for obesity and dyslipidemia may be ascribed to change of lifestyle after migration.
\end{abstract}

\section{Introduction}

The population in Pakistan has a high risk of diabetes and coronary heart disease [1], and common risk factors related to the two conditions are present at early ages [2]. This elevated risk amongst Pakistanis is demonstrated both in Pakistan and abroad [3-5]. Migrants from the Indian subcontinent living in Europe and America have higher rates of cardiovascular risk factors compared to the locals [6-10]. Few articles have compared the prevalence of risk factors in immigrants living in western societies with those still living in their homesteads in the subcontinent [11-14]. Two of these were comparisons of Indians living in London with people living in India. Both showed that BritishIndians had unfavourable cardiovascular risk factor profile compared to those living in India $[11,12]$. One team studied Indians in Australia and their relatives in India and found that women living in Australia had a more desirable risk profile compared to those still living in India. The researchers concluded that the lack of undesirable weight gain was the reason for the lower risk [13]. The population of the Norwegian capital has been increasingly diversified during the last decades, and there is now a large NorwegianPakistanis population in Oslo [15]. The prevalence of obesity and diabetes in Oslo has proven to be very high especially amongst those from Pakistan $[8,16]$. It has been suggested that migration from developing countries to developed countries leads to these changes [12]. No study has so far compared Pakistanis living in Norway with Pakistanis living in Pakistan. It is therefore necessary to find out whether there is an elevated prevalence of risk factors for cardiovascular disease in Pakistanis residing in Oslo compared to those living in the country of origin. In this paper, we compare two Pakistani populations, one in Norway and the other in Pakistan, for cardiovascular risk factors. Most Pakistanis living in Norway are from an area called Kharian, in Punjab, and therefore we chose this area for an epidemiological study. 


\section{Methods}

2.1. Norway. Data were obtained from two populationbased, cross-sectional surveys conducted in Oslo, Norway, between 2000 and 2002 with similar protocol. The Oslo Health Study (HUBRO) was a collaboration between the Norwegian Institute of Public Health, the University of Oslo and the Oslo Municipality (2000-01). All Oslo residents born in $1924,1925,1940,1941,1955,1960$, and 1970 were invited to a health survey. Of these $18,770(46 \%)$ attended [17]. The second survey, the Oslo Immigrant Health Study, was conducted by the Norwegian Institute of Public Health and the University of Oslo in 2002. In this survey individuals born in Turkey, Iran, Pakistan Sri Lanka, or Vietnam between 1942 and 1971 were invited to participate, and the response rate for Pakistani immigrants was $31.7 \%$ [16]. In the present analysis, we have only included participants born in Pakistan. Of these, ten subjects were excluded due to invalid height/weight measurements. A total of 770 participants were included from the Norwegian material; 415 men, and 355 women were included in Norway while in Pakistan 358 men and 872 women were included.

2.2. Pakistan. Data was collected during spring and summer of 2006. Subjects were enrolled from 44 villages from this area, about $150 \mathrm{~km}$ from the capital Islamabad. This is primarily an agricultural community but has developed rapidly in the recent decades due to migration to the west. All participants were 20 years or older and met after fasting for 8-10 hours before the examinations. Verbal information was secured from all participants. Only subjects aged between 30 and 61 were included in the current analysis in order to match the Oslo sampling procedure. The methods for the survey in Pakistan are described in detail elsewhere [18]. From the Pakistani material, 1230 subjects were included, 358 men and 872 women.

2.3. Procedures for Anthropometry Measurements. In Norway, weight was measured on a beam scale. This professional scale comes complete with an attached height rod, where both weight and height can be measured simultaneously. Waist and hip girths were measured with a steel measuring tape [19]. In Pakistan, the height was measured against a wall where a measuring tape was attached. Weight was measured with an electronic scale. Waist and hip girths were measured with a nonelastic plastic tape measure.

The participants in both countries were weighed wearing light clothing.

Normal weight was defined as BMI up to $24.9 \mathrm{~kg} / \mathrm{m}^{2}$, and overweight was BMI between 25 and $29.9 \mathrm{~kg} / \mathrm{m}^{2}$. Obesity was defined as a $B M I \geq 30 \mathrm{~kg} / \mathrm{m}^{2}$ [20]. Waist above $80 \mathrm{~cm}$ for women and $90 \mathrm{~cm}$ for men was labelled high. Waist-hip ratio cutoffs were set at 0.8 and 0.9 for females and males, respectively [21].

2.4. Lipids, Blood Pressure, and Smoking Habits. Total cholesterol and HDL were analysed in both countries using enzymatic methods. Total cholesterol levels higher than
$5.0 \mathrm{mmol} / \mathrm{L}$ were considered high. HDL levels below 0.9 and $1.0 \mathrm{mmol}$ for males and females, respectively, were regarded as low.

In Norway, blood pressure was measured with an automatic device (DINAMAP, Criticon, Tampa, Fla, USA), while a standard sphygmomanometer was used in Pakistan. Systolic pressure above $140 \mathrm{mmHg}$ and diastolic pressure above $90 \mathrm{mmHg}$ were classified as high.

Respondents in both countries were asked about their smoking habits. They were classified as either smokers, nonsmokers or previous smokers.

2.5. Statistics. Mean values are presented with one standard deviation. Student's $t$-test was used to calculate $P$ values when comparing two means.

Age adjusted prevalence and means using direct standardization with averaged weight as the standard population are presented in brackets or below the tables were applicable.

\section{Results}

Four hundred and fifteen Pakistani men and 355 women were included in Norway, while in Pakistan 358 men and 872 women were included. The mean age in Norway was 44.2 years for males and 42.4 for females (Table 1). In Pakistan, the mean age was 46.4 and 44.2 for males and females, respectively.

Both genders had similar height in Norway and Pakistan, but their weight on the other hand was not similar. Pakistanis living in Norway had significantly higher mean weight and BMI (Table 1). Being overweight and obese, in terms of having a BMI between 25 and 30 and above 30, was more commonly seen among Pakistanis in Norway (Table 2). More than one-fifth of the Pakistani males in Norway were obese, while only $7 \%$ of the males in Pakistan had a BMI above 30 .

It was more common for males in Norway to have high waist girth and WHR compared to males in Pakistan. High WHR was more frequently observed in Pakistani female subjects. Pakistani males in Norway had higher waist circumference, as well as hip girth and waist-hip ratio (WHR), compared to males in Pakistan.

Women in Pakistan had higher systolic and diastolic pressure compared to females in Norway (Table 3). Men in Norway had higher systolic pressure compared to men in Pakistan. Hypertension appeared to be more common in Pakistan, especially among females.

Both males and females in Norway had higher total cholesterol compared to their counterparts in Pakistan. Women residing in Norway had higher HDL than women in Pakistan.

Systolic and diastolic blood pressure increased with increasing BMI for both genders in both Norway and Pakistan (Table 4). Not surprisingly, waist and WHR increased with BMI so did total cholesterol. With increasing BMI, HDL decreased in the Norwegian-Pakistanis but increased in those living in Pakistan. The highest standardized beta coefficient was seen for waist girth, with a standardized beta value of 
Table 1: Age and physical characteristics of the Pakistanis in Oslo and in Pakistan. Numbers are mean values with one SD in brackets. $P$ values for difference between Pakistanis and Norwegian-Pakistanis. Age adjusted values below.

\begin{tabular}{|c|c|c|c|c|c|c|}
\hline & \multicolumn{3}{|c|}{ Males } & \multicolumn{3}{|c|}{ Females } \\
\hline & Norway & Pakistan & $P$ value & Norway & Pakistan & $P$ value \\
\hline \multirow{2}{*}{ Age } & $44.2(9.3)$ & $46.4(9.5)$ & \multirow[t]{2}{*}{$<.01$} & $42.4(8.6)$ & $44.2(8.6)$ & \multirow{2}{*}{$<.01$} \\
\hline & 45.2 & 45.3 & & 42.9 & 43.9 & \\
\hline \multirow{2}{*}{ Height $(\mathrm{cm})$} & $170.5(5.9)$ & $170.6(7.5)$ & \multirow[t]{2}{*}{.84} & $156.4(5.6)$ & $156.6(6.0)$ & \multirow{2}{*}{.69} \\
\hline & 170.5 & 170.7 & & 156.5 & 156.6 & \\
\hline \multirow{2}{*}{ Weight (kg) } & 79.8 (11.6) & $67.1(14.1)$ & \multirow[t]{2}{*}{$<.01$} & $71.6(12.9)$ & $64.1(14.2)$ & \multirow{2}{*}{$<.01$} \\
\hline & 79.7 & 67.0 & & 71.6 & 64.0 & \\
\hline \multirow{2}{*}{ BMI } & $27.5(3.5)$ & $23.0(4.5)$ & \multirow[t]{2}{*}{$<.01$} & $29.4(5.0)$ & $26.1(5.5)$ & \multirow{2}{*}{$<.01$} \\
\hline & 27.5 & 23.0 & & 29.4 & 26.1 & \\
\hline \multirow{2}{*}{ Waist $(\mathrm{cm})$} & $94.4(10.2)$ & $86.9(12.8)$ & \multirow[t]{2}{*}{$<.01$} & $89.0(12.0)$ & $90.5(12.9)$ & \multirow{2}{*}{.05} \\
\hline & 94.7 & 86.6 & & 89.2 & 90.5 & \\
\hline \multirow{2}{*}{ Hip (cm) } & $100.4(6.8)$ & $94.3(9.9)$ & \multirow[t]{2}{*}{$<.01$} & $104.6(9.8)$ & 105.5 & \multirow{2}{*}{.21} \\
\hline & 100.5 & 94.2 & & 104.6 & 105.5 & \\
\hline \multirow{2}{*}{ Waist/Hip } & $0.94(0.07)$ & $0.92(0.07)$ & \multirow[t]{2}{*}{$<.01$} & $0.85(0.08)$ & $0.86(0.07)$ & \multirow{2}{*}{.08} \\
\hline & 0.94 & 0.92 & & 0.85 & 0.86 & \\
\hline
\end{tabular}

TABle 2: Prevalence of obesity (per 100) among Pakistanis and Pakistanis residing in Oslo. Age adjusted values in brackets.

\begin{tabular}{lccc}
\hline Males & Norway & Pakistan & $P$ value \\
\hline BMI $>25$ & $56(56)$ & $23(23)$ & $<.01$ \\
BMI $>30$ & $22(22)$ & $7(7)$ & $<.01$ \\
High waist & $63(64)$ & $36(35)$ & .01 \\
High WHR & $69(70)$ & $60(59)$ & .01 \\
\hline Females & & & \\
\hline BMI $>25$ & $40(40)$ & $33(33)$ & $<.01$ \\
BMI $>30$ & $40(41)$ & $23(23)$ & $<.01$ \\
High waist & $73(73)$ & $76(76)$ & .28 \\
High WHR & $70(71)$ & $82(82)$ & $<.01$ \\
\hline
\end{tabular}

High waist: above 90 for males and 80 for females.

High WHR: above 0.9 for males and 0.8 for females.

$P$ values for difference between Pakistanis and Norwegian-Pakistanis.

approximately 0.8 for all groups. The standardized beta value for WHR was 0.48 and 0.52 for males in Norway and Pakistan, respectively. Females however had a considerably lower standardized beta value for WHR. Females in Pakistan had the lowest.

Smoking habits were unfortunately not recorded in all of those living in Pakistan. However, the results obtained in Pakistan $(n=401)$ were similar to those in Norway. In Pakistan, $40.5 \%$ of the males and $2.8 \%$ females were current smokers; in Norway, $34 \%$ of the males and $3.8 \%$ of the females were smokers. None of the females in Pakistan said they were previous smokers, while $2.2 \%$ of the females in Norway said so. Among the males in Pakistan, 7.4\% said they were previous smokers, of the Norwegian-Pakistanis, $18.5 \%$ were previous smokers.

\section{Discussion}

We demonstrated high prevalence of obesity and cardiovascular risk factors in both populations, this is in line with earlier studies $[11,12]$. Obesity, overweight, and having high levels of lipids were more common in Norway, while high blood pressure was seen more frequently in Pakistan. We believe that the two populations are comparable because the majority of the Pakistanis living in Norway actually migrated from this particular area in Pakistan, an area called Kharian in the district of Gujrat. Therefore, it is reasonable to postulate that the populations are genetically and culturally comparable. The differences we observe between the two populations could therefore be due to the effects of migration and changes in lifestyle from a low-income to a high-income country.

The difference in weight and BMI are of such a magnitude that they cannot be explained by possible measuring error. This is particularly true for the males; the difference is more than $10 \mathrm{~kg}$, whilst it is almost $8 \mathrm{~kg}$ in women. This difference is reflected in the BMI; increased BMI in Oslo among the Pakistani population may only be explained by added weight in this population, since height remains the same in both populations.

The difference between the populations in waist and hip girth are also evident among the males. The men living in Norway have almost a waist of more than seven $\mathrm{cm}$ greater than the males in Pakistan; similarly, the hip is also more than six $\mathrm{cm}$ larger in the Norwegian-Pakistanis. The differences between the females on the other hand are small. Some women in Pakistan might have been reluctant to remove their clothes for the measurement of the waist and hip girth even though same gender investigators did all the measurements. Women living in rural Pakistan might also have had a higher number of pregnancies, which could have resulted in a higher waist, hip, and waist-hip ratio. On the other hand, the WHR 
Table 3: Differences in clinical features among Pakistanis in Oslo and in Pakistan. Numbers are mean values with one SD in brackets. $P$ values for difference between Pakistanis and Norwegian-Pakistanis. Age adjusted values below.

\begin{tabular}{|c|c|c|c|c|c|c|}
\hline & \multicolumn{3}{|c|}{ Males } & \multicolumn{3}{|c|}{ Females } \\
\hline & Norway & Pakistan & $P$ value & Norway & Pakistan & $P$ value \\
\hline \multirow{2}{*}{ SysBP } & $128.8(14.2)$ & $123.7(16.8)$ & $<.01$ & $120.9(18.2)$ & $125.5(17.1)$ & \multirow{2}{*}{$<.01$} \\
\hline & 129.3 & 123.4 & & 121.3 & 125.5 & \\
\hline \multirow{2}{*}{ DiaBP } & $78.0(10.1)$ & $79.4(11.4)$ & .07 & $71.3(11.0)$ & $80.8(10.5)$ & \multirow{2}{*}{$<.01$} \\
\hline & 78.3 & 79.3 & & 71.5 & 80.8 & \\
\hline \multirow{2}{*}{$\%$ Sys $\geq 140$} & 18 & 20 & .59 & 14 & 24 & \multirow{2}{*}{$<.01$} \\
\hline & 19 & 19 & & 14 & 24 & \\
\hline \multirow{2}{*}{$\%$ Dia $\geq 90$} & 13 & 28 & $<.01$ & 5 & 31 & \multirow{2}{*}{$<.01$} \\
\hline & 13 & 28 & & 5 & 31 & \\
\hline \multirow{2}{*}{ TotChol $(\mathrm{mmol} / \mathrm{L})$} & $5.4(1.0)$ & $4.5(1.0)$ & $<.01$ & $5.1(1.0)$ & $4.7(1.0)$ & \multirow{2}{*}{$<.01$} \\
\hline & 5.5 & 4.5 & & 5.1 & 4.7 & \\
\hline \multirow{2}{*}{$\mathrm{HDL}(\mathrm{mmol} / \mathrm{L})$} & $1.1(0.2)$ & $1.0(0.5)$ & .38 & $1.2(0.3)$ & $1.0(0.4)$ & \multirow{2}{*}{$<.01$} \\
\hline & 1.1 & 1.0 & & 1.2 & 1.0 & \\
\hline
\end{tabular}

TABLE 4: Association between BMI and other clinical features.

\begin{tabular}{lccccccccc}
\hline & \multicolumn{4}{c}{ Males } & \multicolumn{4}{c}{ Females } \\
& $\beta$ & $P$ value & $\beta$ & $P$ value & $\beta$ & $P$ value & $\beta$ & $P$ value \\
\hline SysBP & 0.19 & $<.01$ & 0.35 & $<.01$ & 0.15 & $<.01$ & 0.25 & $<.01$ \\
DiaBP & 0.11 & .02 & 0.35 & $<.01$ & 0.07 & .18 & 0.27 & $<.01$ \\
Waist & 0.78 & $<.01$ & 0.84 & $<.01$ & 0.78 & $<.01$ & 0.80 & $<.01$ \\
WHR & 0.48 & $<.01$ & 0.52 & $<.01$ & 0.27 & $<.01$ & 0.12 & $<.01$ \\
TotChol & 0.01 & .80 & 0.20 & $<.01$ & 0.12 & .01 & 0.10 & .01 \\
HDL & -0.16 & $<.01$ & 0.11 & .06 & -0.24 & .00 & 0.09 & .02 \\
\hline
\end{tabular}

Standardized coefficients, only adjusted for age.

did not increase as steeply with increasing BMI among the females in Pakistan as it did amongst the Pakistani females in Norway. One study has shown that expatriate Indian women in Australia did in fact have a better risk profile than their counterparts still living in India [13].

There are large differences in the levels of total cholesterol especially for the males. The difference between females in the two populations was also considerable. However, this is not surprising since obesity was highly increased among the Pakistani population residing in Oslo.

Several studies have showed that people from South Asia living in western societies have a relatively low level of physical activity $[22,23]$. This might be the cause of the high level of adiposity among the Pakistanis living in Norway. In addition, higher consumption of unhealthy fatty foods, which is available in Oslo due to privileged income and sedentary lifestyle, may have contributed to the observed conditions.

There are some interesting differences in blood pressure between these two populations. The Pakistanis living in Norway have lower pressures, except for the systolic pressure in males. We do not have data on use of antihypertensive drugs in Pakistan, but we find it reasonable to believe that such medication might be less common than in Norway. Due to low access to doctors, undiagnosed hypertension might be more common in rural Pakistan compared to Oslo. Earlier studies have showed that the awareness about hypertension is low in Pakistan, and few patients have had their blood pressure measured $[24,25]$. It is also important to note that the blood pressure was measured differently in the two populations. Dinamap was used in Norway, in Pakistan we used a standard sphygmomanometer. The different measuring methods might have yielded different results. Cautiousness should therefore be applied when comparing blood pressure in the two populations and interpreting these results. High levels of hypertension have been reported earlier amongst Pakistanis [3, 4], although, some large studies have reported considerably lower prevalence of hypertension $[26,27]$. Comparison between most of these studies is hampered by diverging measuring techniques.

Smoking is common amongst Pakistani males both in Norway and in Pakistan; women, however, are fortunately spared. This pattern of smoking has been demonstrated in several studies that have looked at smoking habits amongst Pakistanis in Pakistan and abroad $[2,4,5]$.

\section{Conclusion}

Our data demonstrate differences in cardiovascular risk factors in these two populations, possibly as a consequence of migration and related changes in lifestyle. More research is needed on the modification of lifestyle and food habits following migration. Nevertheless, Pakistanis living in Norway have proven to have higher levels of diabetogenic and cardiovascular risk factors and therefore should be treated as "high risk group" for both prevention and treatment.

\section{References}

[1] M. Gupta, N. Singh, and S. Verma, "South Asians and cardiovascular risk: what clinicians should know," Circulation, vol. 113, no. 25, pp. e924-e929, 2006.

[2] P. Joshi, S. Islam, P. Pais et al., "Risk factors for early myocardial infarction in South Asians compared with individuals in other countries," Journal of the American Medical Association, vol. 297, no. 3, pp. 286-294, 2007. 
[3] T. H. Jafar, F. H. Jafary, S. Jessani, and N. Chaturvedi, "Heart disease epidemic in Pakistan: women and men at equal risk," American Heart Journal, vol. 150, no. 2, pp. 221-226, 2005.

[4] T. H. Jafar, Z. Qadri, and N. Chaturvedi, "Coronary artery disease epidemic in Pakistan: more electrocardiographic evidence of ischaemia in women than in men," Heart, vol. 94, no. 4, pp. 408-413, 2008.

[5] F. P. Cappuccio, D. G. Cook, R. W. Atkinson, and P. Strazzullo, "Prevalence, detection, and management of cardiovascular risk factors in different ethnic groups in South London," Heart, vol. 78, no. 6, pp. 555-563, 1997.

[6] S. S. Anand, S. Yusuf, V. Vuksan et al., "Differences in risk factors, atherosclerosis, and cardiovascular disease between ethnic groups in Canada: the Study of Health Assessment and Risk in Ethnic groups (SHARE)," Lancet, vol. 356, no. 9226, pp. 279-284, 2000.

[7] P. M. McKeigue and M. G. Marmot, "Mortality from coronary heart disease in Asian communities in London," British Medical Journal, vol. 297, no. 6653, p. 903, 1988.

[8] A. K. Jenum, I. Holme, S. Graff-Iversen, and K. I. Birkeland, "Ethnicity and sex are strong determinants of diabetes in an urban Western society: implications for prevention," Diabetologia, vol. 48, no. 3, pp. 435-439, 2005.

[9] E. Flowers, C. Molina, A. Mathur et al., "Prevalence of metabolic syndrome in South Asians residing in the United States," Metabolic Syndrome and Related Disorders, vol. 8, no. 5, pp. 417-423, 2010.

[10] S. N. Rajpathak, L. S. Gupta, E. N. Waddell et al., "Elevated risk of type 2 diabetes and metabolic syndrome among Asians and south Asians: results from the 2004 New York City HANES," Ethnicity \& Disease, vol. 20, no. 3, pp. 225-230, 2010.

[11] J. V. Patel, A. Vyas, J. K. Cruickshank et al., "Impact of migration on coronary heart disease risk factors: comparison of Gujaratis in Britain and their contemporaries in villages of origin in India," Atherosclerosis, vol. 185, no. 2, pp. 297-306, 2006.

[12] D. Bhatnagar, I. S. Anand, P. N. Durrington et al., "Coronary risk factors in people from the Indian subcontinent living in West London and their siblings in India," Lancet, vol. 345, no. 8947, pp. 405-409, 1995.

[13] D. Mahajan and M. A. Bermingham, "Risk factors for coronary heart disease in two similar Indian population groups, one residing in India, and the other in Sydney, Australia," European Journal of Clinical Nutrition, vol. 58, no. 5, pp. 751$760,2004$.

[14] S. U.B. Tennakoon, B. N. Kumar, D. B. Nugegoda, and H. E. Meyer, "Comparison of cardiovascular risk factors between Sri Lankans living in Kandy and Oslo," BMC Public Health, vol. 10, no. 1, article 654, 2010.

[15] K. Glenday, B. N. Kumar, A. Tverdal, and H. E. Meyer, "Cardiovascular disease risk factors among five major ethnic groups in Oslo, Norway: the Oslo Immigrant Health Study," European Journal of Cardiovascular Prevention and Rehabilitation, vol. 13, no. 3, pp. 348-355, 2006.

[16] B. N. Kumar, H. E. Meyer, M. Wandel, I. Dalen, and G. Holmboe-Ottesen, "Ethnic differences in obesity among immigrants from developing countries, in Oslo, Norway," International Journal of Obesity, vol. 30, no. 4, pp. 684-690, 2006.

[17] A. J. Søgaard, R. Selmer, E. Bjertness, and D. Thelle, "The Oslo Health Study: the impact of self-selection in a large, population-based survey," International Journal for Equity in Health, vol. 3, no. 1, Article ID 3, 2004.
[18] N. Zahid, B. Claussen, and A. Hussain, "Diabetes and impaired glucose tolerance in a rural area in Pakistan and associated risk factors," Diabetes and Metabolic Syndrome: Clinical Research and Reviews, vol. 2, no. 2, pp. 125-130, 2008.

[19] A. J. Søgaard and R. Selmer, "The Oslo Health Study," September 2006.

[20] WHO, "Physical Status: the use and interpretation of anthropometry," Report of a WHO Expert Committee, WHO, Geneva, Switzerland, 1995.

[21] K. G. M. M. Alberti, P. Zimmet, and J. Shaw, "Metabolic syndrome-a new world-wide definition. A consensus statement from the International Diabetes Federation," Diabetic Medicine, vol. 23, no. 5, pp. 469-480, 2006.

[22] A. K. Jenum, S. A. Anderssen, K. I. Birkeland et al., "Promoting physical activity in a low-income multiethnic district: effects of a community intervention study to reduce risk factors for type 2 diabetes and cardiovascular disease: a community intervention reducing inactivity," Diabetes Care, vol. 29, no. 7, pp. 1605-1612, 2006.

[23] R. Bhopal, C. Fischbacher, E. Vartiainen, N. Unwin, M. White, and G. Alberti, "Predicted and observed cardiovascular disease in South Asians: application of FINRISK, Framingham and SCORE models to Newcastle Heart Project data," Journal of Public Health, vol. 27, no. 1, pp. 93-100, 2005.

[24] T. Ashfaq, Q. Anjum, H. Siddiqui, S. Shaikh, and E. A. Vohra, "Awareness of Hypertension among patients attending Primary Health Care Centre and Outpatient Department of tertiary care hospital of Karachi," Journal of the Pakistan Medical Association, vol. 57, no. 8, pp. 396-399, 2007.

[25] K. Ahmad and T. H. Jafar, "Prevalence and determinants of blood pressure screening in Pakistan," Journal of Hypertension, vol. 23, no. 11, pp. 1979-1984, 2005.

[26] A. S. Shera, F. Jawad, and A. Maqsood, "Prevalence of diabetes in Pakistan," Diabetes Research and Clinical Practice, vol. 76, no. 2, pp. 219-222, 2007.

[27] T. H. Jafar, A. S. Levey, F. H. Jafary et al., "Ethnic subgroup differences in hypertension in Pakistan," Journal of Hypertension, vol. 21, no. 5, pp. 905-912, 2003. 


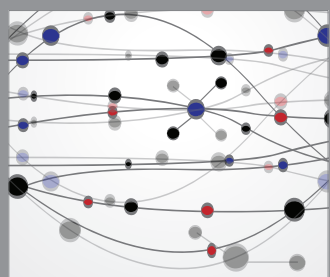

The Scientific World Journal
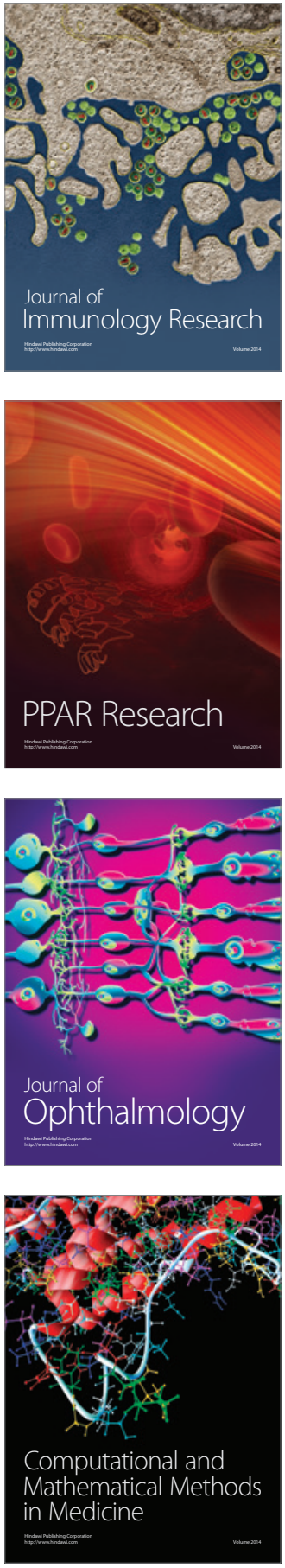

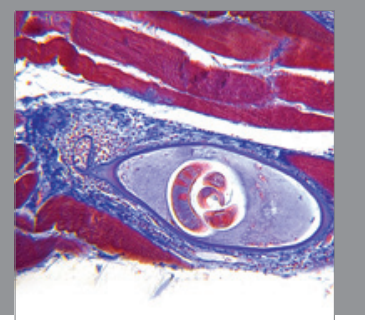

Gastroenterology

Research and Practice
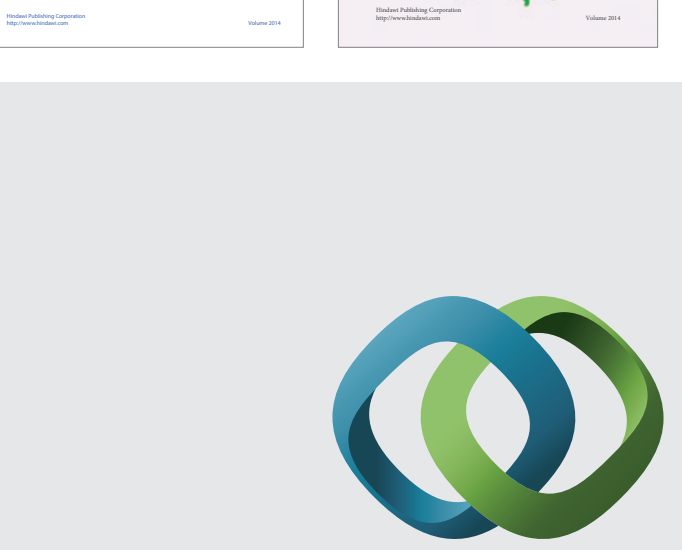

\section{Hindawi}

Submit your manuscripts at

http://www.hindawi.com
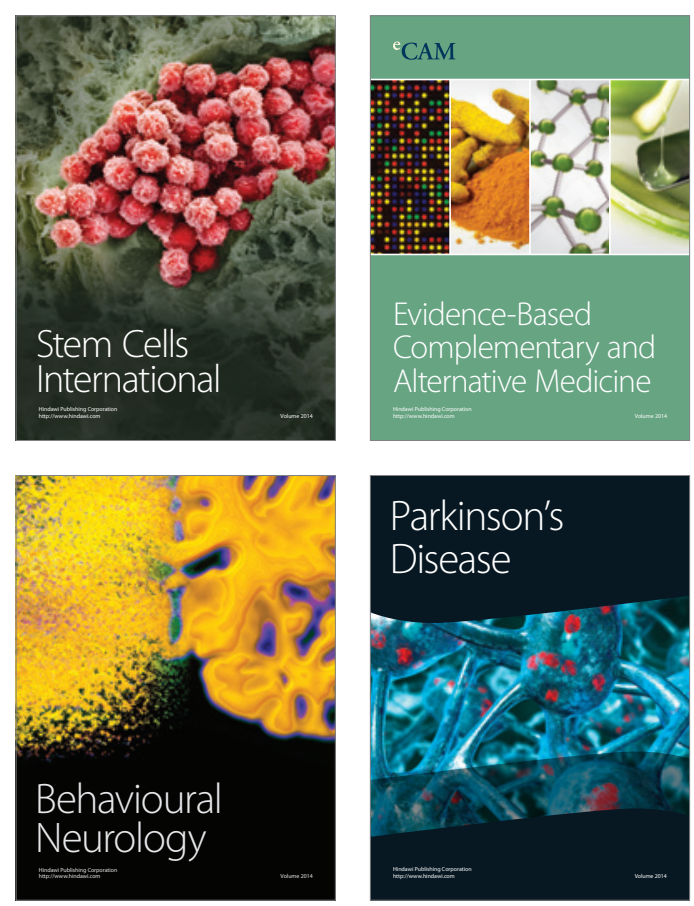

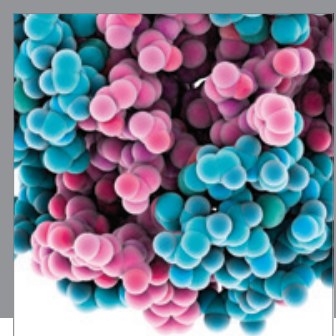

Journal of
Diabetes Research

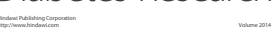

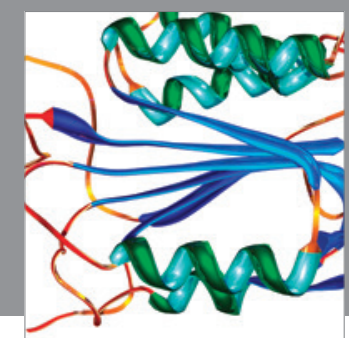

Disease Markers
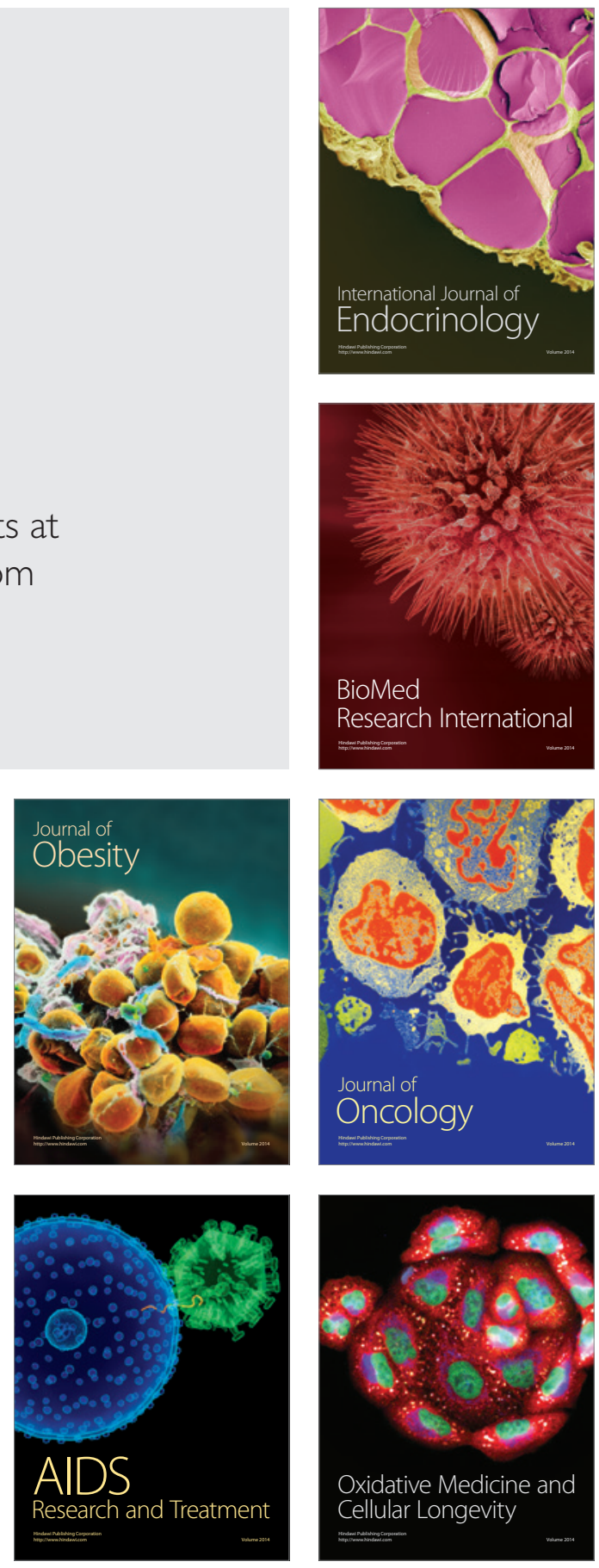